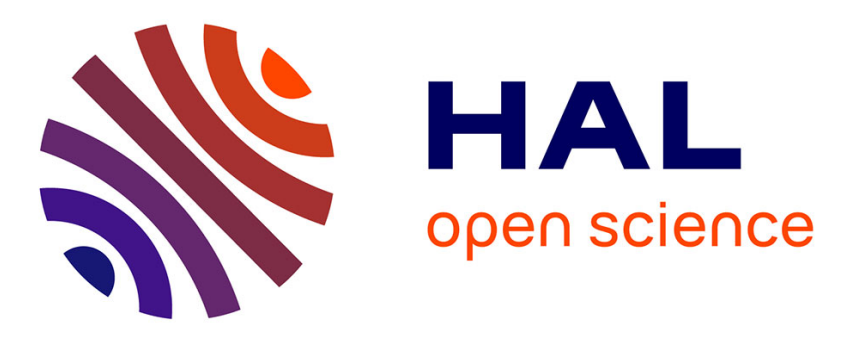

\title{
Three-dimensional in situ observations of short fatigue crack growth in magnesium
}

King Andrew, Wolfgang Ludwig, Michael Herbig, Jean-Yves Buffiere, T.J Marrow, N. Stevens, A. A. Khan

\section{- To cite this version:}

King Andrew, Wolfgang Ludwig, Michael Herbig, Jean-Yves Buffiere, T.J Marrow, et al.. Threedimensional in situ observations of short fatigue crack growth in magnesium. Acta Materialia, 2011, 59 (17), pp.6761-6771. 10.1016/j.actamat.2011.07.034 . hal-00646640

\section{HAL Id: hal-00646640 \\ https://hal.science/hal-00646640}

Submitted on 30 Nov 2011

HAL is a multi-disciplinary open access archive for the deposit and dissemination of scientific research documents, whether they are published or not. The documents may come from teaching and research institutions in France or abroad, or from public or private research centers.
L'archive ouverte pluridisciplinaire HAL, est destinée au dépôt et à la diffusion de documents scientifiques de niveau recherche, publiés ou non, émanant des établissements d'enseignement et de recherche français ou étrangers, des laboratoires publics ou privés. 


\title{
Three dimensional in-situ observations of short fatigue crack growth in magnesium
}

\author{
A. King ${ }^{1}$, W. Ludwig ${ }^{1,2}$, M. Herbig ${ }^{2}$, J.-Y. Buffière ${ }^{2}$, A.A. Khan ${ }^{3}$, N. Stevens ${ }^{4}$, \\ T.J. Marrow ${ }^{5}$ \\ ${ }^{1}$ European Synchrotron Radiation Facility, Grenoble, BP 220, 38043 Grenoble, \\ France \\ ${ }^{2}$ Université de Lyon, MATEIS, UMR5510 CNRS, 69621 Villeurbanne, France \\ ${ }^{3}$ Pakistan Institute of Nuclear Science \& Technology, Islamabad, Pakistan \\ ${ }^{4}$ Materials Performance Centre, School of Materials, University of Manchester, M1 \\ 7HS, UK \\ ${ }^{5}$ Department of Materials, University of Oxford, Oxford, OX1 3PH, UK
}

\begin{abstract}
Three-dimensional (3D) short fatigue crack growth behaviour in a cast magnesium alloy Elektron 21 was studied using a combination of X-ray diffraction contrast tomography (DCT) and microtomography at the European Synchrotron Radiation Facility (ESRF). A 3D map of grain shapes and crystallographic orientations was produced in a miniature fatigue specimen using DCT. A focused ion beam (FIB) instrument was used to introduce small notches in selected grains. Synchrotron microtomography was used to study the evolution of fatigue cracks from these notches during interrupted in-situ fatigue cycling. Stage I crack growth occurred preferentially on the basal plane of the Magnesium hexagonal close packed crystal, with local crack growth rates between 4 and $40 \mathrm{~nm} /$ cycle. Retardations in the local crack growth rate were observed in certain grains, and at certain grain boundaries. The observed interactions between the crack and the polycrystalline microstructure can be explained using Schmid factors and a development of the tilt-twist model of Zhai and Wilkinson [1].
\end{abstract}

Keywords: fatigue; x-ray diffraction (XRD); magnesium alloys; grain boundary structure

\section{Introduction}

Cracks are three-dimensional, and they interact with the microstructure of materials, which is also three-dimensional. During constant stress amplitude loading, crack growth rates generally increase exponentially with the crack length since the mechanical crack driving force increases with crack length, unless significant relaxation occurs in response to the effect of the crack (i.e. for displacement controlled tests), or in the case of complex residual stress gradients for example. Hence the majority of the lifetime of a crack in a structural component may be spent when the crack is quite short, and uncertainties in short crack propagation behaviour can have a strong influence on lifetime prediction. There is therefore a need to good understanding of the behaviour of short cracks, which may be short relative to the microstructure length scale (i.e. grain size, for example, in which case interactions 
between cracks and microstructure are important), or the component scale, in which case there are issues of elastic plastic behaviour and constraint to be addressed [2-5]. Such cracks are in the regime within which the experimental study and modelling of crack behaviour are most difficult, and in which detailed understanding and data are least sound. In the last twenty years, significant experimental and theoretical efforts have been devoted to the characterisation and modelling of short fatigue crack propagation [e.g. 6, 7]. However, crack growth rate predictions for such defects remain far from completely satisfactory. The consequent uncertainty in the prediction of crack behaviour and lifetime can lead to conservatism in engineering design and may result in unnecessary and uneconomic repair of structures in which the early stages of cracking are identified in service.

Studies of short crack behaviour are generally restricted to the crack length at the surface, which provides little or no information about the development of the crack shape in the bulk. Some understanding of crack shapes can be obtained by methods such as serial metallographic sectioning, which can be used to reveal the crack shape at the end of a fatigue test [8-10]. Similarly, interrupted testing and fracture can determine the typical development of crack shape [11]. "Beach-marking', i.e. defining the position of the crack tip by varying the cyclic stress amplitude, has also been used to record the development of individual cracks [12]. These observations have shown that physically short cracks (i.e. those which have a size greater than the microstructure scale) may have an approximately semi-circular shape. In some cases, particularly when microstructure has a strong influence on crack development, a simple relationship between the crack length as measured on the surface and length in depth cannot necessarily be assumed [13]. Indeed, very little is found by such techniques concerning the crack shape at the very early stage of growth when its size is comparable to that of the surrounding microstructure.

Computed X-ray tomography $[14,15]$ is a relatively new technique that can be used to visualise the internal structure of materials. In its classical form, this non-destructive technique uses two-dimensional (2D) radiographic projections of a sample to reconstruct a three-dimensional (3D) map of the X-ray attenuation coefficient of the material. In the last ten years, significant progress has been made in terms of resolution with both the availability of new third generation synchrotron X-ray sources and new detectors [15]. A spatial resolution (i.e. pixel size) better than $1 \mu \mathrm{m}$ can now be achieved in 3D, which is well suited to the investigation of fatigue cracks [16-19]. In particular, the partially coherent radiation from a third generation synchrotron provides phase contrast enhancement under appropriate conditions, allowing features smaller than the pixel size to be detected [16].

X-ray diffraction contrast tomography (DCT) is an emerging technique for mapping grain shape and crystal orientation in polycrystalline materials, non-destructively and in 3D [20-22]. It is a natural complement to synchrotron microtomography for the investigation of fatigue crack growth, because it allows the grain microstructure to be characterised prior to fatigue loading. In contrast, high-resolution post-test techniques such as serial sectioning that use focussed-ion-beams to reconstruct the microstructure have limited application to large volumes and also can investigate only the damaged and deformed microstructure after failure, i.e. the damage chronology is lost. By combining computed tomography with diffraction contrast tomography of the undamaged microstructure the interaction of the growing crack with the grains in 
the bulk of the material can be studied. This enables in-depth studies of early crack growth, including observations of the interaction of cracks with the grains and grain boundaries of polycrystals [19,23]. In particular, Herbig et al studied this combination of techniques to study the propagation of a fatigue crack in a body centred cubic titanium sample containing around 1000 grains [19]. The local crack propagation rate was measured, and the crystallographic character of the crack plane was described in terms of combinations of expected slip planes. However, interpretation was made difficult by the fact that several slip systems, with high multiplicity, are active in the material studied [19]. To favour a more quantitative interpretation, in this work a magnesium alloy was used.

In hexagonal close packed magnesium the limited number of available slip systems restricts the number of crystallographic planes that are available for easy crack growth. The primary slip system is $\langle 10-10\rangle(0002)$ (the close packed directions on the hexagonal basal planes). This limits easy plasticity, and crack growth rates are affected by the crystal orientation relative to crack plane [24]. Plasticity in magnesium alloys at room temperature is dominated by this slip system and $\{10-12\}$ twinning [25]. Twinning can allow the reorientation of grains or parts of grains during loading. Twinning has been observed to interact with fatigue crack initiation and propagation in single crystals, or in rolled or extruded microstructures with strong texture which inhibit basal slip [24,26,27]. The cast material used in the present work has a much weaker texture, and is therefore contains a higher proportion of grains in which basal slip is available for deformation. Primatic slip $\langle 10-10\rangle\{10-12\}$ has also been observed in fatigue specimens at higher stresses, but has a greater resistance to dislocation movement [27].

This paper reports observations, obtained by DCT and in-situ high-resolution X-ray tomography of miniature fatigue specimens, of the early stages of nucleation and growth of short fatigue cracks in magnesium alloy Elektron21, nucleated within selected grains at fine notches machined by a focused ion beam (FIB). The principal objective was to study the interaction of stage I crystallographic cracks with grain boundaries.

\section{Experimental Details}

The magnesium alloy Elektron 21 used in this work was provided by Magnesium Elektron Ltd. as cast plates, measuring $200 \mathrm{~mm} \times 200 \mathrm{~mm} \times 25 \mathrm{~mm}$. They were in the $\mathrm{T} 6$ condition $\left(8\right.$ hours at $520^{\circ} \mathrm{C}$, hot water quenched, 16 hours at $\left.200^{\circ} \mathrm{C}\right)$. The nominal chemical composition is given in Table 1 . The tensile properties of the asreceived microstructure given in Table 2 are the average of three tensile specimens tested. (60 mm long, $10 \mathrm{~mm}$ wide and $2 \mathrm{~mm}$ thick with a short gauge section $\sim 4 \mathrm{~mm}$ long and $\sim 2 \mathrm{~mm}$ wide) [28].

Table 1: Chemical Composition in weight percent.

\begin{tabular}{|l|l|l|l|l|l|l|}
\hline $\mathrm{Zn}$ & $\mathrm{Zr}$ & $\mathrm{Nd}$ & $\mathrm{Gd}$ & Other rare earth & Others & $\mathrm{Mg}$ \\
\hline 0.31 & 0.5 & 2.5 & 1.3 & 0.1 & $<0.01$ & Balance \\
\hline
\end{tabular}


Table 2: Mechanical Properties

\begin{tabular}{|l|l|l|}
\hline $\begin{array}{l}0.2 \% \text { Proof Stress } \\
(\mathrm{MPa})\end{array}$ & $\begin{array}{l}\text { Tensile Strength } \\
(\mathrm{MPa})\end{array}$ & $\begin{array}{l}\text { Elongation } \\
(\%)\end{array}$ \\
\hline 175 & 265 & 7 \\
\hline
\end{tabular}

Miniature fatigue specimens were designed for the experiment, as shown in Figure 1. The sample length is $14 \mathrm{~mm}$, and the gauge diameter is $1 \mathrm{~mm}$. Their size and microstructure were selected to suit the two imaging techniques, which have certain requirements regarding sample size and microstructure. It has been previously shown that fatigue cracks and stress corrosion cracks can be successfully imaged, with the assistance of phase contrast, using reconstructed volumes that have a voxel size of $0.7 \mu \mathrm{m}$ (a voxel is the 3D analogue of a pixel) [16-19, 23]. Using a $2048^{2}$ pixel detector, this implies that the sample diameter should be less than $1.4 \mathrm{~mm}$. The diameter should also be small enough to allow at least $10 \%$ transmission of the incoming X-ray beam through the thickest part of the sample. DCT is capable of mapping a few thousand grains in a single scan in suitable microstructures $[21,22]$. Thus a further requirement is that the grain size be large enough so as not to exceed this number of grains in the volume of interest. For this study a sample gauge diameter of $1 \mathrm{~mm}$ was used, and the T6 material was subsequently heat treated at $520^{\circ} \mathrm{C}$ to increase the average grain size to around $55 \mu \mathrm{m}$, to give around 2500 grains in the mapped volume. The studied sample is weakly textured, with a tendency for the $\{0002\}$ poles to be aligned with the tensile axis of about two multiples of a random texture, based on the grain orientations determined by DCT. Several small nickel spheres (diameter $150 \mu \mathrm{m}$, just visible in figure 1) were fixed to the sample in the vicinity of the gauge volume. These served as fiducial reference markers to aid the alignment of different datasets, and when orienting the sample in the FIB to introduce the notches in the desired region. 


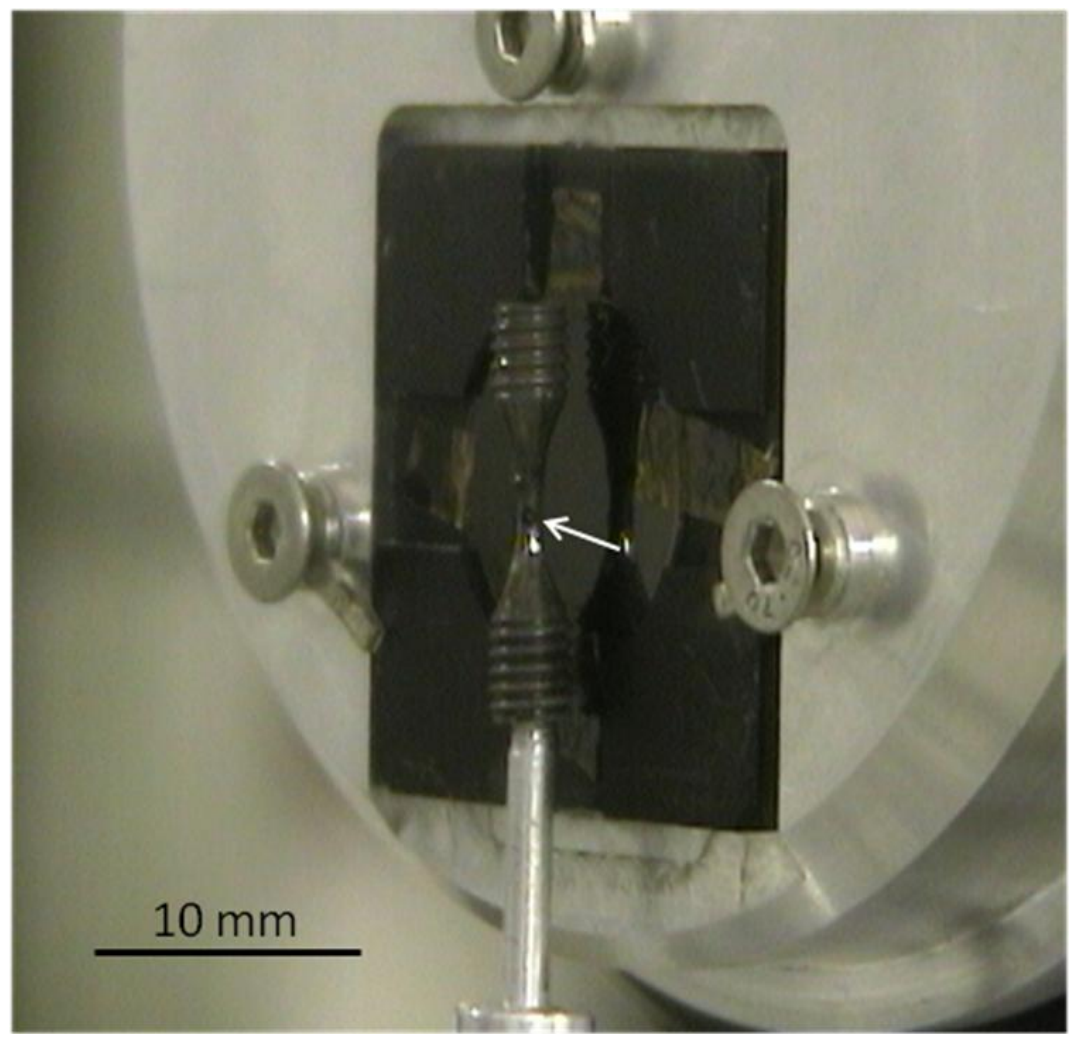

Figure 1. Miniature fatigue sample mounted on beam line.

The imaging experiments were performed at the European Synchrotron Radiation Facility (ESRF) in Grenoble on the high-resolution tomography beam line (ID19) on separate experimental periods within beam time allocation MA-423. For both techniques, images were acquired using a FReLoN camera coupled to a scintillator screen with magnifying optics [29].

For DCT, it is necessary to capture both diffraction spots and the absorption contrast image of the sample on the detector. A pixel size of $1.75 \mu \mathrm{m}$ was used, giving a $3.5 \mathrm{~mm}$ field of view. A sample to detector distance of $5.1 \mathrm{~mm}$ gave sufficient solid angle coverage to acquire diffraction spots from the first five $\{$ hk.l $\}$ reflections. A beam of $20.5 \mathrm{keV}$ with energy bandwidth $\Delta \mathrm{E} / \mathrm{E}=10^{-4}$ was used. A set of 7200 diffraction contrast images was recorded during a full $360^{\circ}$ rotation of the sample. The procedure for reconstruction of the grain shapes and their crystal orientations is described elsewhere $[21,22]$. The reconstructed volumes were re-scaled to match the $0.7 \mu \mathrm{m}$ voxel size of the tomographic reconstructions for ease of comparing the two datasets.

For tomography, optics giving an effective pixel size of $0.7 \mu \mathrm{m}$ were used. A multilayer monochromator was used to select a beam with an energy of $20.5 \mathrm{keV}$ and a bandwidth of $\Delta \mathrm{E} / \mathrm{E}=10^{-2}$ for optimal flux. The distance between the sample and detector was set to $40 \mathrm{~mm}$ in order to obtain some phase contrast in the reconstructed 3D images, a mode of imaging which is known to enhance the visibility of sub-pixel sized defects [16]. A series of 1000 radiographs taken during a $180^{\circ}$ rotation of the sample was used to reconstruct the $3 \mathrm{D}$ volumes using a filtered back projection algorithm. 
The specimen was first characterised by DCT to provide a 3D grain map. Five fine notches to initiate cracks were made at different locations at the centre of gauge section by FIB milling. For three of these, an attempt was made to place notches in specific grains, selected by inspection of the DCT data, where the notch was oriented parallel to the basal plane and was therefore inclined to the tensile axis. Part of the sample was removed by gentle manual polishing to expose the selected grains at the surface. Two further notches, normal to the loading axis, were placed in arbitrary grains. Each notch was approximately $90 \mu \mathrm{m}$ long, with an estimated depth of $30 \mu \mathrm{m}$, with a mouth opening of $\sim 10 \mu \mathrm{m}$.

The fatigue loading was performed using a cyclic loading machine designed for insitu tomographic measurements (i.e. compact size and minimal vibration levels). The load train is supported by an X-ray transparent Perspex tube to allow images to be acquired through a $180^{\circ}$ rotation of the sample [18]. The tension-tension fatigue loading used a sinusoidal waveform at a frequency of $5 \mathrm{~Hz}$ with a maximum stress of $130 \mathrm{MPa}$ and R-ratio (minimum/maximum load) of 0.25 . The cycling was interrupted at intervals for tomographic scanning at 500, 1000, 2000, 2500, 3000, 3500, 4000, 5000 cycles, then at intervals of 250 to 500 cycles up to 10250 cycles when the test was suspended. The scans were performed with the sample under maximum load to increase the crack opening, and thus its visibility. 


\section{Results and analysis}

Although five notches were prepared, only one notch exhibited significant fatigue crack development. This notch was aligned perpendicular to the stress axis, and was inserted in an arbitrary grain. It is the results from this notch that are presented here. Figure 2 shows sections through the reconstructed volume at the position of the notch, after 500 and after 10500 cycles. The crack can be observed to have begun to propagate from the notch in the first observation at 500 cycles. Both the crack and small, highly attenuating Nd-rich precipitates are resolved. Although it is possible to use automatic segmentation of these images to visualise the 3D shape of the crack, this is insufficient for the purpose of crack dimension measurements due to errors caused by the relatively low attenuation contrast between the crack and the magnesium matrix and also because of phase contrast artefacts. Consequently, the position of the fatigue crack front was traced manually by inspection of individual 2D slices from the 3D datasets to determine the coordinates of the crack front as it developed throughout the experiment. The error in determining the position of the crack front was estimated to be five voxels (i.e. $3.5 \mu \mathrm{m}$ ). An algorithm (described in the Appendix) was implemented in Matlab (Matlab 7.4, The Mathworks Inc, Natick, MA) to determine the crack growth velocity as a function of position, using these data.

These tomographic reconstructions were aligned with the grain map determined by DCT, as were the manually determined crack front data. Figure 3 shows a rendering
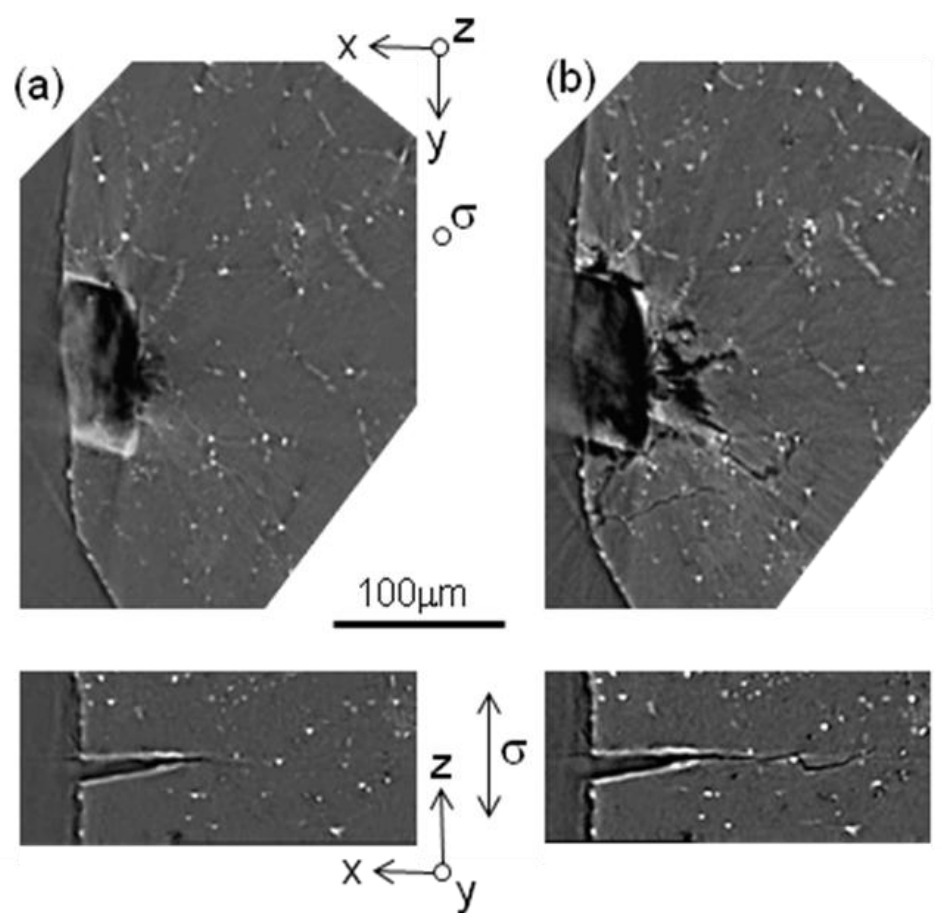

Figure 2. Reconstructed sections after (a) 500 and (b) 10,500 fatigue cycles, showing the crack growing from the FIB notch, and the microstructure of the material. The white particles are Nd-rich precipitates. 
of a region of interest around the crack in which the grains have been rendered partially transparent. This emphasises the 3D nature of the crack, which deviates strongly from the x-y plane.

\subsection{D and 3D representation of data}

The 3D representations of the data contain a very large amount of information, and hence are complex to view, complicating the task of describing the behaviour of the crack as it interacts with the microstructure. It is useful to obtain a 2D visualisation of the crack. An example is shown in figure 4, which is a projected view of the crack looking along the tensile axis (z), which is normal to the $x-y$ plane. The free surface of the sample and the FIB notch are on the left hand side of the view. The projected crack has an approximately semi-elliptical shape. The small "holes" that appear in the crack (labelled with arrows in (a)) are regions where the opening displacement is too small for the crack to be segmented using simple threshold methods. These may be removed by image processing methods. Each pixel in the projected image of the crack was defined as a crack element (with a size of $0.7 \times 0.7 \mu \mathrm{m}$ ), which could have various parameters associated with it such as the grain orientation at its corresponding $\mathrm{X}-\mathrm{Y}-\mathrm{Z}$ position in the $3 \mathrm{D}$ dataset, the crack plane or the crack growth rate, for example. Although the crack exhibits some branching (see Fig 3), the branches do not tend to overlap vertically. In these cases, the element was assigned to the largest overlapping branch. Such areas where there may be more than one crack element occupy less than $20 \%$ of the total surface.

This projected view of the crack may be coloured to display the parameters at each element. For example, Figure 4 is coloured according to the orientations of the grains

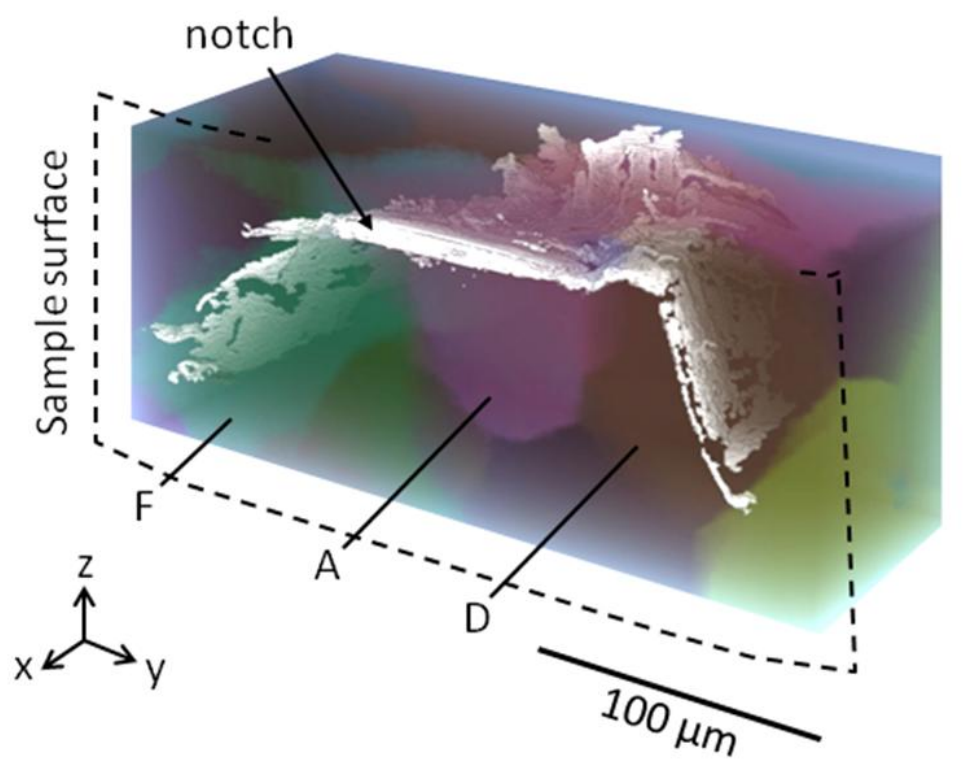

Figure 3. 3D rendering showing the crack (white) and the grains (coloured, semi-transparent). Colour denotes basal plane orientation according to the key in figure 4. 
the crack passes through. The colour is defined by the grain basal plane orientation relative to the sample. The colour scheme, which is also used in the $3 \mathrm{D}$ rendering in figure 3 , is illustrated for a stereographic projection in figure 4(c). The angular rotation of the basal plane normal about the z-axis determines the colour, while the saturation of the colour, from white to near-black, depends on the angle between the basal plane normal and the z-axis. Grains in which the basal plane is perpendicular to the tensile axis are lightest.

To the left and right of the notch (figure 3), the crack grows along approximately flat planes that are inclined to the notch, whereas as the crack propagates away from the notch into the sample (towards the rear of figure 3), it splits into several "fingers" lying on approximately parallel planes whose normal vectors are inclined at approximately $30^{\circ}$ to the tensile axis. Excluding the area of the notch, approximately $50 \%$ of the crack surface is inclined by more than $30^{\circ}$ from the $x-y$ plane. The variations in the crack plane can be quantified. To do this, at each element in the projected crack, the 3D positions of the voxels of the crack surface associated with a region of interest of $8 \times 8 \times 8 \mu \mathrm{m}^{3}$ around the element were selected. The local crack plane was obtained by fitting to these points. The local crack plane, displayed on the
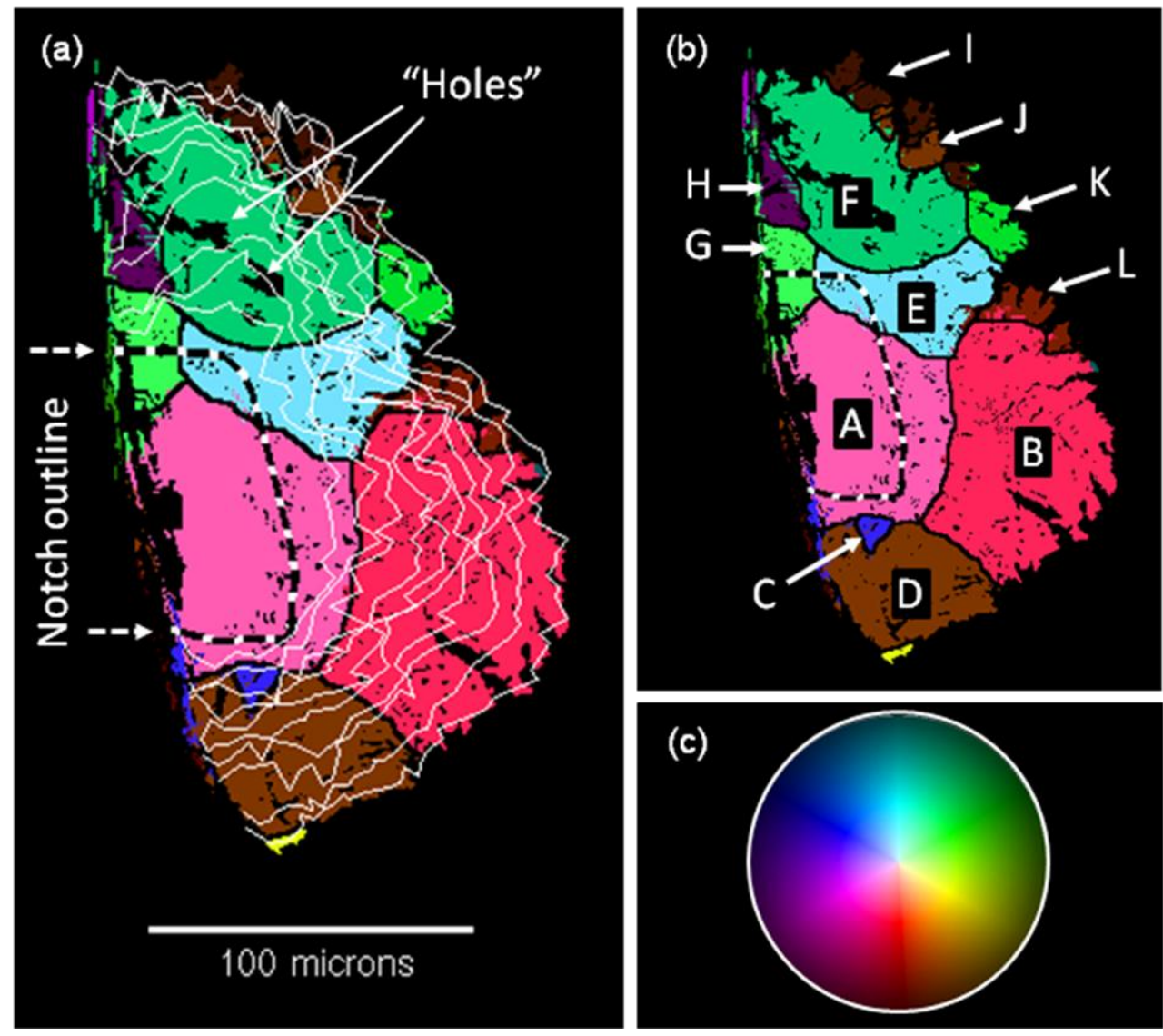

Figure 4. (a) Plan view of crack from along the loading (z) axis. The crack is coloured according to the basal plane orientation of the grains intersected by the crack. Black lines mark the grain boundaries. Superimposed white lines are the manually segmented crack fronts (increments of $\sim 1000$ cycles). The black lines are the grain boundary intersections with the surface. (b) The labels A-L that are used in the text to describe the grains. (c) The colour map used to display orientation (stereographic projection). 


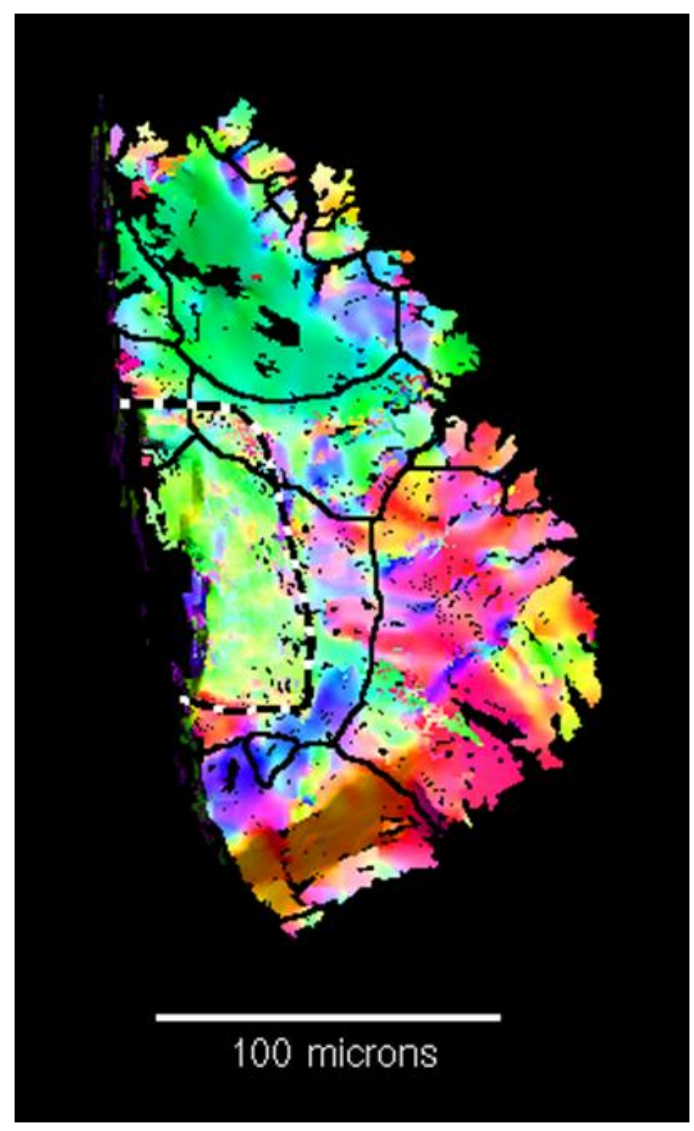

Figure 5. The local orientation of the crack plane. Colour represents the plane orientation relative to the sample, as in Figure 4.

2D projection of the crack with the same orientation-colour map used for figures 3 and 4 , is shown in figure 5 .

The 3D information about the crack plane and the basal plane orientations can be visually compared using these 2D images. For example, comparison of Figure 4 and 5 reveals a significant proportion of corresponding regions of similar colour, indicating that the crack has a tendency to propagate on the basal plane. This is shown with greater sensitivity in Figure 6, which presents the angular deviation between the crack plane and the local basal plane. The low values identify the regions of basal propagation. Higher values tend to be observed around the periphery of the crack, and where the crack intersects certain grain boundaries. Excluding the notch, approximately $54 \%$ of the crack surface is inclined by less than $30^{\circ}$ from the basal plane.

In the single crystal work of Iida et al, twinning was observed to interact with crack propagation [24]. The crack morphology obtained in this work does not reveal evidence of twinning. However, the resolution is insufficient to detect fine twins, and it is possible that these may occur. 


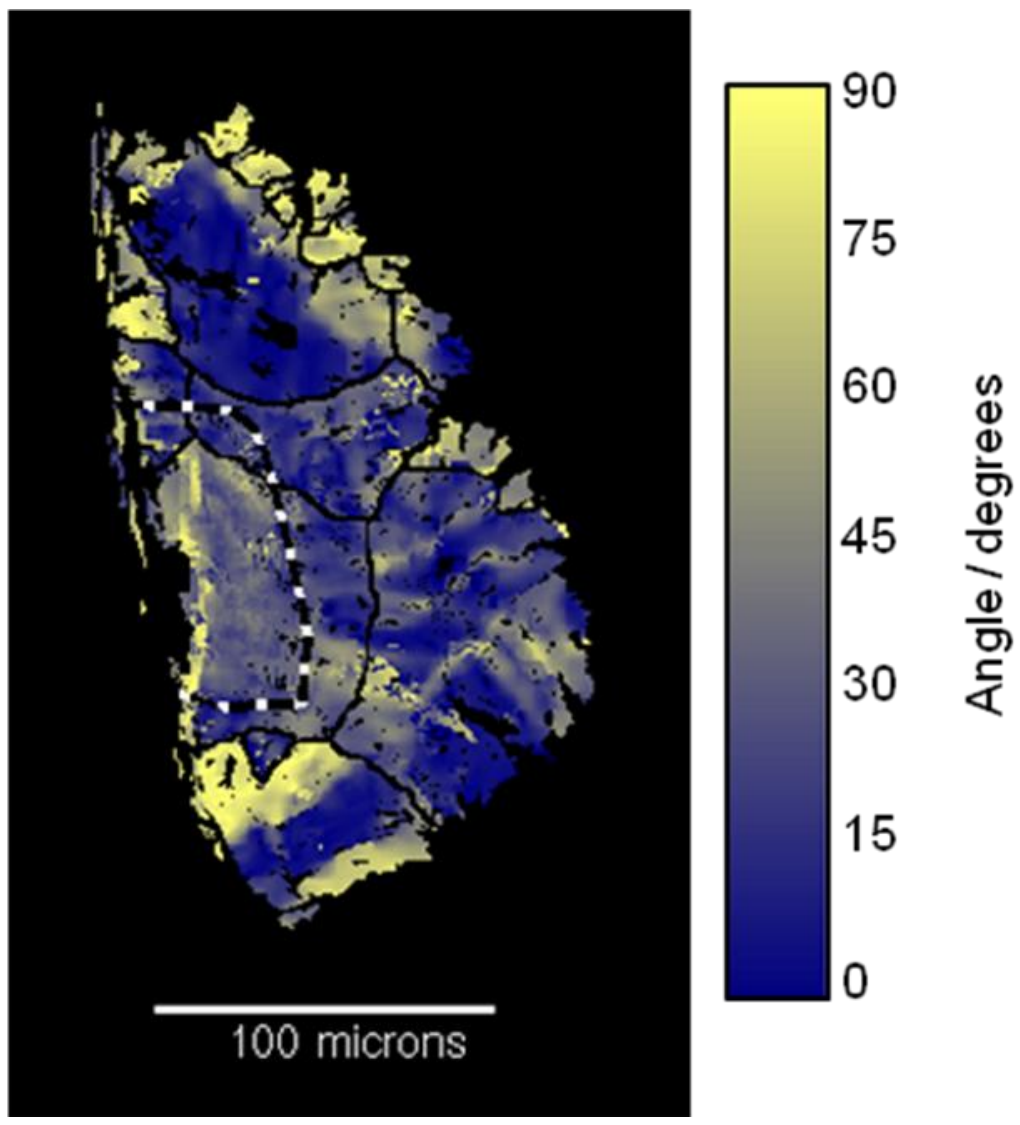

Figure 6. Deviation between the crack plane and the crystallographic basal plane.

\subsection{Crack growth rate}

Data, extracted from the tomographic reconstructions, for the total surface length (2c) and the projected depth (a) for the observed crack are summarised in figure 7 . The extent of propagation is insufficient for fit anything more complex than a linear relationship, and the average crack increment per cycle, $\mathrm{N},(\mathrm{dc} / \mathrm{dN}$ and da/dN) are 8 and $7 \mathrm{~nm} /$ cycle respectively.

When visualised in 3D the crack growth behaviour is complex. Figure 4(a) shows the projections of the manually segmented crack fronts at increments of $\sim 1000$ cycles. Because the surface of the crack is non-planar, the crack growth rate cannot be accurately visualised directly from these projections. However, they provide a qualitative indication of the crack propagation, showing that the crack front is retarded at the surface in the region of grains $G$ and $H$. It is clear that surface observations of crack growth rates can be inadequate to describe its $3 \mathrm{D}$ development. The algorithm described in the Appendix was used to calculate the local growth rate at each point along the observed crack fronts. The data were smoothed for visualisation by presenting the median value of the nearest ten crack growth rate data points for each position on the crack surface. The resulting data for local growth rate as a function of position are shown in Figure 8. This shows the crack growth rate varies considerably with position, varying between 4 and $40 \mathrm{~nm} /$ cycle. Several regions of fast crack growth are clearly observed on either side of the originating FIB notch. The average rate is around $9 \mathrm{~nm} / \mathrm{cycle}$, which is consistent with the values 
obtained from the projected dimensions of the crack. The crack growth rate shows no tendency to increase with distance from the notch, and indeed tends to be lower with increasing distance. Slow crack growth is observed particularly in grains I, J and L at the top and right of figure 4.

\section{Discussion}

The average fatigue crack growth rate extracted from the observations is around 7-9 $\mathrm{nm} /$ cycle. Comparative data on short fatigue crack propagation in magnesium alloys (i.e. crack length $<1 \mathrm{~mm}$ ) are quite limited. Wang et al [30,31] report data for cast AM50 Mg-Al alloy in vacuum (yield stress $130 \mathrm{MPa}$, tensile strength $200 \mathrm{MPa}$ ). At constant stress amplitude (140 MPa) at room temperature the crack propagation could be described by a constant growth rate of approximately $300 \mathrm{~nm} /$ cycle for a crack length of less than $300 \mu \mathrm{m}$. At stress amplitude of $120 \mathrm{MPa}$, the crack growth rate averaged $70 \mathrm{~nm} /$ cycle below $150 \mu \mathrm{m}$, and $200 \mathrm{~nm} /$ cycle between $150 \mu \mathrm{m}$ and 300 $\mu \mathrm{m}$. Gall et al [32] present measurements made in a cast AM60B Mg-Al alloy (yield stress $150 \mathrm{MPa}$, tensile strength $285 \mathrm{MPa}$ ). Growth rates at a stress amplitude of 90 MPa were constant for crack lengths between 50 and $300 \mu \mathrm{m}$, varying between 7 to $12 \mathrm{~nm} /$ cycle in vacuum and $18-30 \mathrm{~nm} /$ cycle in water vapour. The observed average growth rates of around $8 \mathrm{~nm} /$ cycle in ambient air in this work are therefore consistent with such data. In both cases transgranular cracking was the predominant mode, having a crystallographic character associated with slip planes.

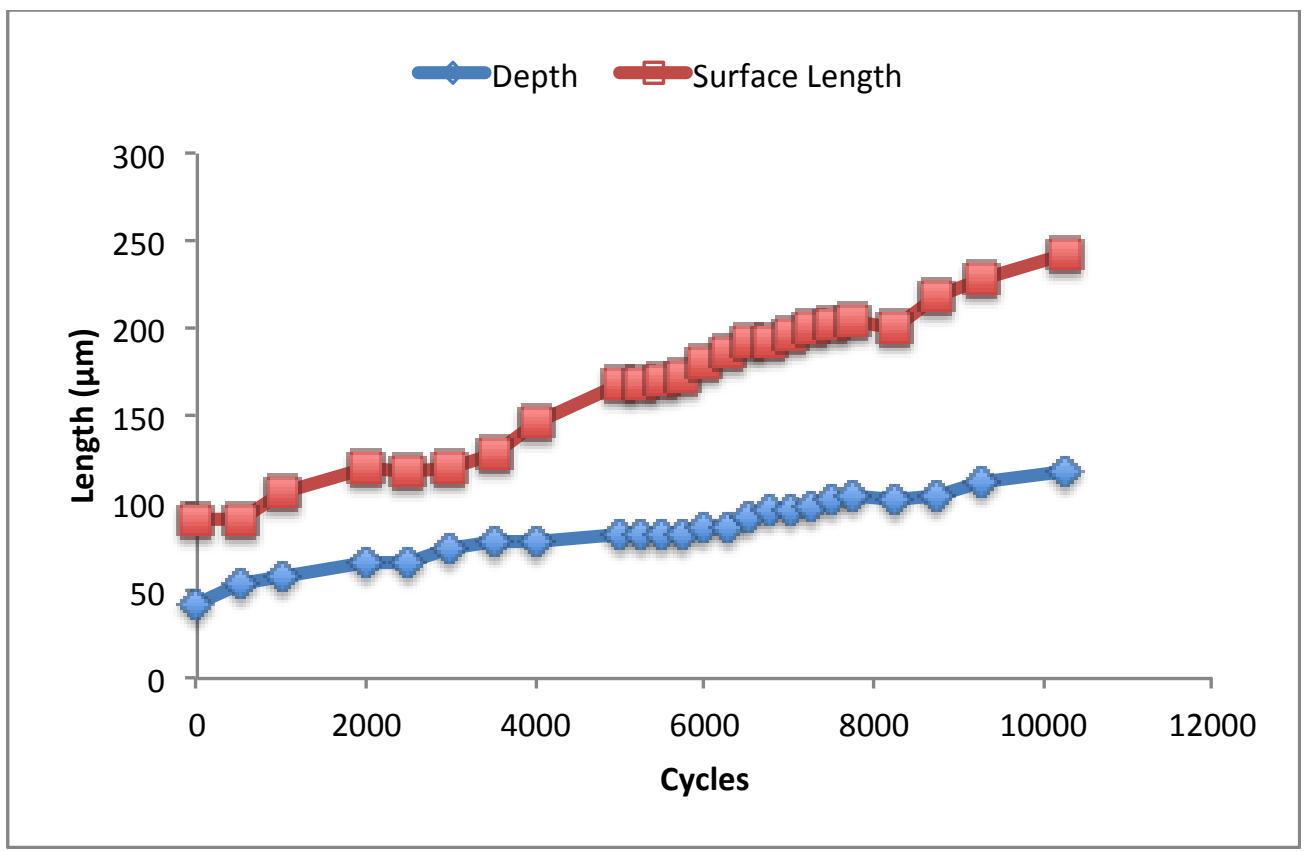

Figure 7. Development of crack surface length and depth with number of fatigue cycles extracted from tomography observations. 


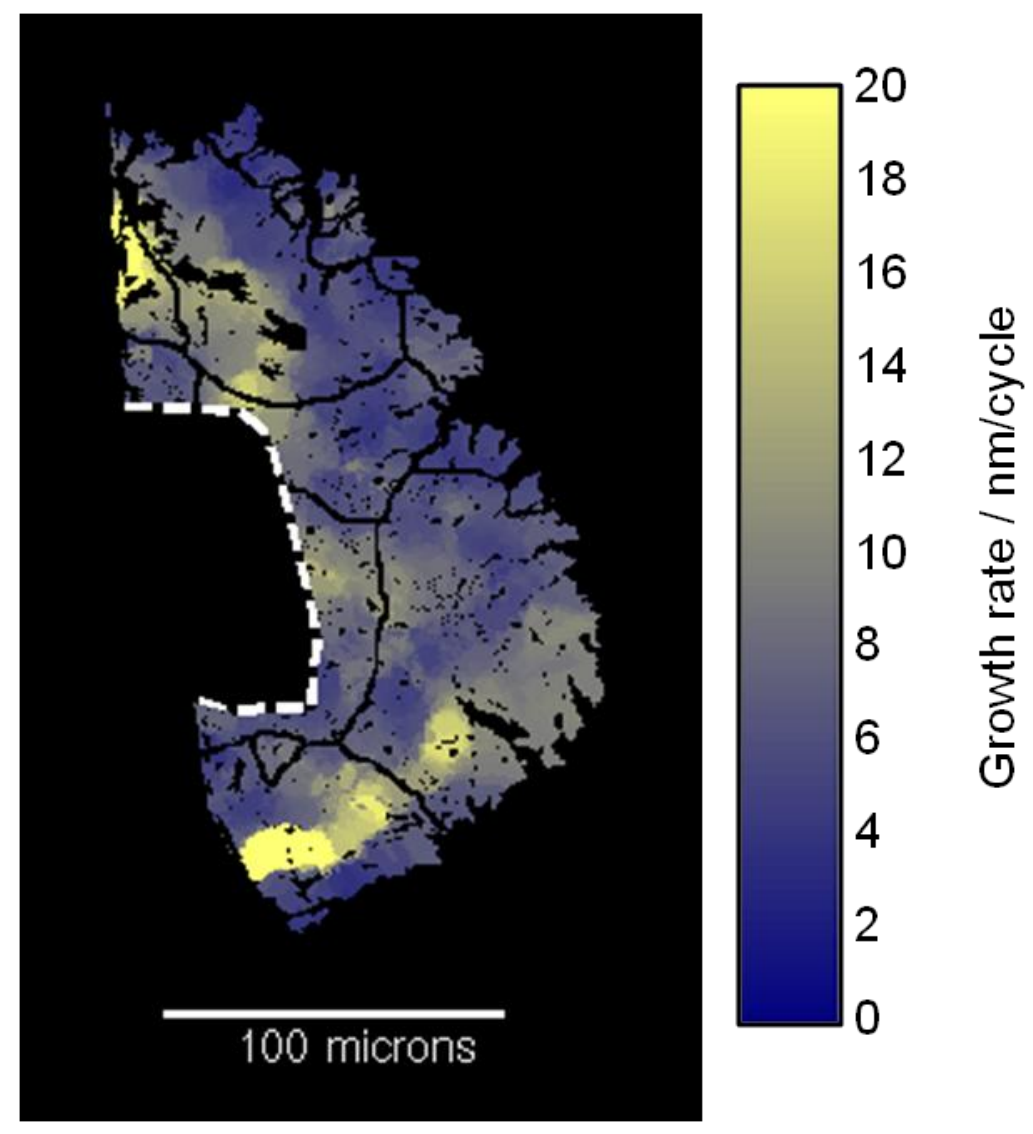

Figure 8. Local crack growth rate. Note that while the maximum observed rate was $40 \mathrm{~nm} /$ cycle, the colour scale varies between 0 and $20 \mathrm{~nm} /$ cycle to better reveal local variations.

The combined use of the CT and DCT datasets for the fatigue crack and microstructure helps to reveal its characteristic behaviour. There is a tendency for the crack to be oriented with the basal plane, and those regions where this is the case tend to exhibit the higher growth rates (see, for example, grains D and F). Lower rates appear to be associated with the non-crystallographically oriented regions that developed towards the end of the experiment, particularly in grains D, I, J and K. The crack therefore has the general appearance of a predominantly stage I crystallographic fatigue crack. Such cracks are known to be exhibit variable crack growth rates [eg 9] as is observed here.

Closer examination of the crack growth rates shows regions of local growth rate variation. Referring to the grain labels in figure 4, some regions of interesting behaviour are as follows: Fast, crystallographic crack growth occurs in grains A, D and F, compared with slower crystallographic growth in B. Fast, non-crystallographic growth is seen in grain $\mathrm{H}$. Slower crack growth occurs around grain C, between grains $\mathrm{E}$ and $\mathrm{L}$, and along the crack front in grains $\mathrm{I}, \mathrm{J}$ and $\mathrm{K}$. The unique data obtained by combined DCT and CT allows the crack tip environment at these locations to be examined to determine whether these may be understood in terms of the Schmid factor in the grains, the character of the grain boundaries, and also the orientation of the slip planes relative to the crack initiating notch. 


\subsection{Grain Schmid factor}

The Schmid factor describes the fraction of the shear stress resolved onto each slip system to an applied tensile stress. Stage I short fatigue crack growth is driven by slip, and therefore the maximum Schmid factor may represent the driving force for crack growth [33]. In single crystals, short fatigue crack growth has been observed to occur on the slip planes with the highest Schmid factor [33]. The Schmid factor of the most highly stressed slip system in each grain through which the crack passed is shown in Figure 9. For this analysis, the applied stress has been assumed to be uniform and parallel to the loading axis, so each grain is effectively treated as an isolated single crystal. This neglects both the effect of the notch or crack on the local stress field, and also the effect of the elastic anisotropy of the grains. Both of these factors will complicate the local stress field, but are neglected as a first approximation. It should be noted that because of the symmetry of the hexagonal system there is only one plane available for easy slip, the basal plane. Therefore the Schmid factor can vary between 0 and 0.5 depending on the orientation of the grain. In other crystal systems, for example cubic structures, the higher multiplicities of slip planes means that that some will always have non-zero Schmid factors. For example in face-centred cubic systems it can be shown that the minimum Schmid factor is $\sim 0.27$.

From Figure 9 it can be seen that the Schmid factor is high (greater than 0.25) in most of the grains (i.e. A-G, K). In particular, the crack grows quickly across grain $\mathrm{F}$

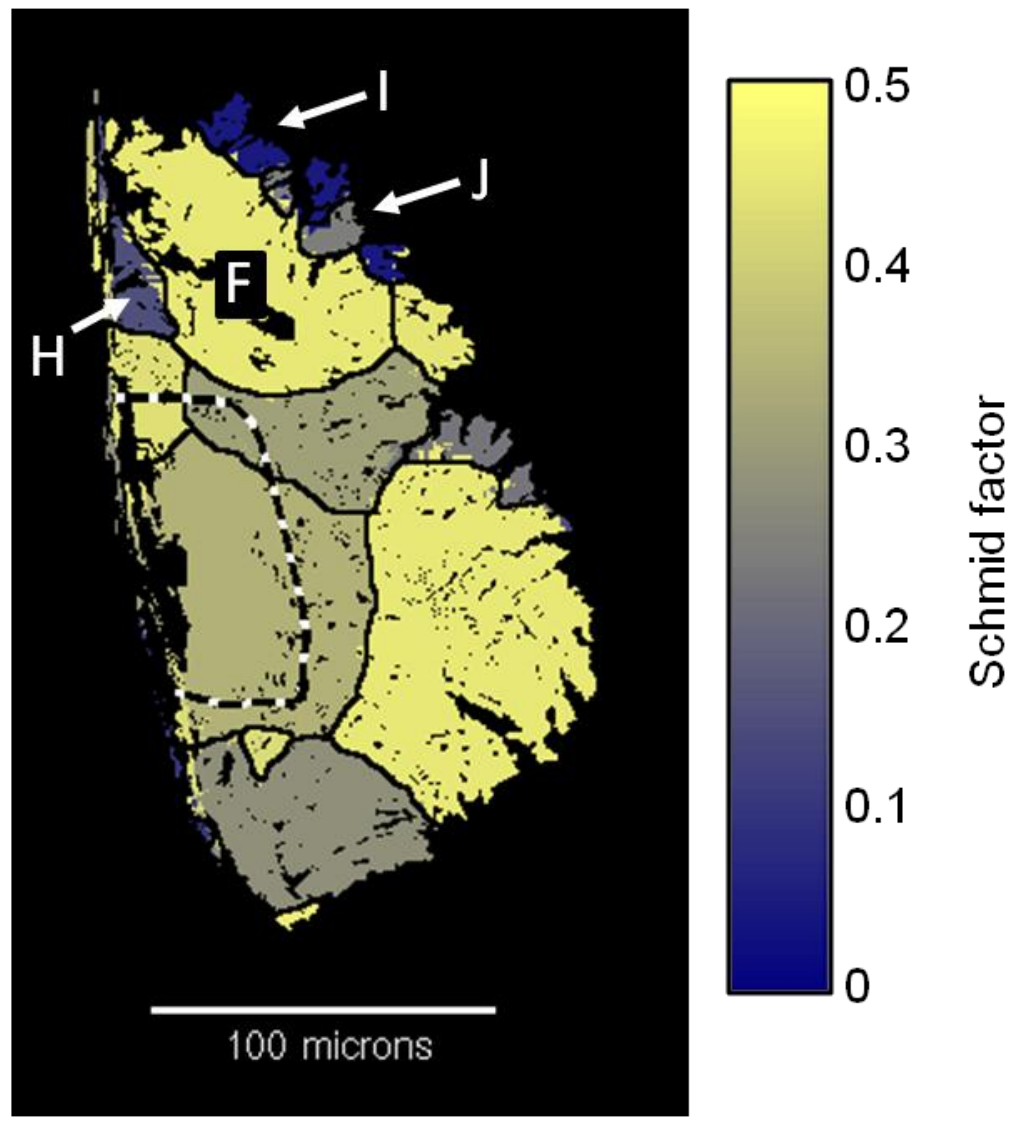

Figure 9. Schmid factor for the most activated basal slip system in each grain. 
(Schmid factor 0.46), before dramatically slowing on reaching grains I and J (Schmid factors 0.05 and 0.25 respectively). In this region of reduced crack growth rate, the crack plane tends to be normal to the applied load, which is a characteristic of stage II crack growth.

Interestingly, in grain $\mathrm{H}$, which lies between grain $\mathrm{F}$ and the sample surface, quite fast crack growth is observed despite its low Schmid factor (0.16). Examination of Figure 6 shows that the crack does not grow on the basal plane in this grain. It appears, from the successive positions of the crack front, that the faster crack growth in grain $\mathrm{F}$ causes grain $\mathrm{H}$ to develop a ligament at the sample surface. Such behaviour is illustrated in [34]. The ligament subsequently fails at a higher growth rate (presumably driven by the increased crack opening around it as the overall crack length increased). The crack path through the ligament appears to be defined by the earlier failure of grain $\mathrm{F}$, as indicated in Figure 5.

The implication of this simplistic analysis is that the Schmid factor may provide a first order approximation to the tendency for stage I crack growth. Local arrangements of the crack geometry may, however, have additional effects, such as those observed for grain $\mathrm{H}$.

\subsection{Tilt/twist character of the grain boundaries}

It has been argued for many years that stage I fatigue cracks should be retarded or arrested at grain boundaries where the slip plane deviates [35,36]. Recently, Zhai and Wilkinson used two angular measures (twist and tilt), to characterise the misorientation between slip planes at grain boundaries in a 2D study of crack growth [1]. In their nomenclature, twist is the angle between the traces of the two slip planes on the boundary plane, and tilt is the angle between the traces of the slip planes on the surface of the sample. In their investigation, the boundary plane was assumed to be normal to the surface plane. The twist angle was identified as being the more important parameter to describe the resistance to crack propagation. Re-initiation at multiple sites along the intersection between the crystallographic crack plane and the grain boundary would tend to cause crack branching, with a consequent reduction in crack tip strains due to mechanical shielding from the intact ligaments of material between these parallel cracks.

In this work, the orientation of the grain boundary can be obtained in 3D by identifying those voxels lying on the boundary between two grains, and then fitting a plane through these. The twist angle can then be calculated readily. The trace of the slip plane on the surface of the sample has no meaning within the $3 \mathrm{D}$ volume. A more general definition of the tilt angle is required. This was done at each grain boundary by determining the necessary twist angle, as a rotation about the grain boundary normal, to bring the traces of the slip planes on the boundary plane into alignment. The tilt angle is then the remaining angle between the slip planes, about a rotation axis that lies in the plane of the grain boundary. These stages are illustrated in figure 10.

For basal plane slip in the hexagonal crystal system, the maximum tilt and twist values can vary between 0 and $90^{\circ}$. Values for those boundaries traversed by the crack are shown in Figure 11. It is can be seen that several regions of slow crack 

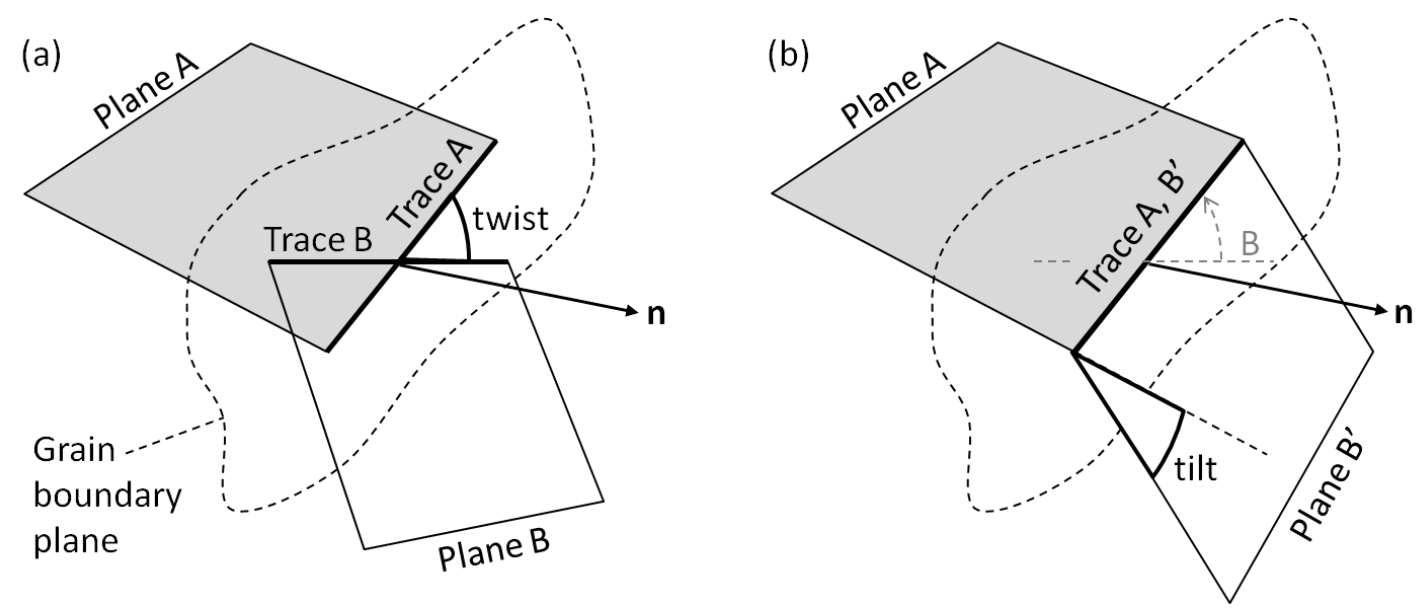

Figure 10. The calculation of twist and tilt angles in 3D. (a) Twist is the angle between the traces of the slip planes on the grain boundary. (b) Tilt is the remaining angle after applying the twst angle to one of the slip planes.

propagation (i.e. between grains $\mathrm{E}$ and $\mathrm{L}$ and around grain $\mathrm{C}$ ) are associated with boundaries of either high twist or tilt values (Between $\mathrm{E}$ and L, tilt of $60^{\circ}$, twist of $88^{\circ}$, between $\mathrm{C}$ and $\mathrm{D}$ tilt of $86^{\circ}$, twist of $71^{\circ}$ ). High twist values are also observed between grain $\mathrm{F}$ and grains $\mathrm{I}$ and $\mathrm{J}\left(78^{\circ}\right.$ and $72^{\circ}$ respectively) where the crack decelerates. These observations support the hypothesis that stage I crack propagation is retarded at boundaries with large misorientations of the slip plane.

\subsection{Compatibility between the notch and the slip plane}

The notch initiates the crack growth and its strain field influences the early stage I crack growth. It is interesting to assess the compatibility of the slip planes with the notch, particularly in the grains within which the notch lies. Here we define a quantity, the notch twist angle, to describe this. The notch is horizontal, with the shape shown in the figures. The notch tip opening angle is here assumed to be $0^{\circ}$. The ideal crack growth direction is assumed to be radial from the edges of the notch. Thus a plane may be defined that is normal to the growth direction at each point. The angle between the trace of the notch (in this case horizontal) and the trace of the slip plane in the grain is calculated on this plane. The analysis is equivalent to that for the tilt/twist calculation at grain boundaries, with the plane of the notch replacing one of the slip planes. The twist angle obtained will be referred to as the notch twist angle. The results of this calculation for the grains in which the crack propagated are shown in figure 12. The large variations of the notch twist angle within grains D and F are a consequence of the slip plane normal being close to the radial crack growth direction.

The effect of the notch twist angle might be responsible for the slow growth in grain $\mathrm{B}$, despite its high Schmid factor of 0.45. In parts of grains D and F (marked with arrows in figure 12), the notch plane is close to the basal plane. Particularly in grain $\mathrm{F}$, rapid early crack propagation is observed starting from the compatible region. However, throughout grain B the basal plane is twisted with respect to the notch, as shown by the relatively high value of the notch twist angle $\left(>30^{\circ}\right)$. The crack initiating from the notch within grain A therefore splits into several parallel fingers in order to propagate locally on the basal planes. There is a twist of around $15^{\circ}$ between the plane of the notch and the basal plane in grain $\mathrm{A}$, followed by a further $14^{\circ}$ twist 

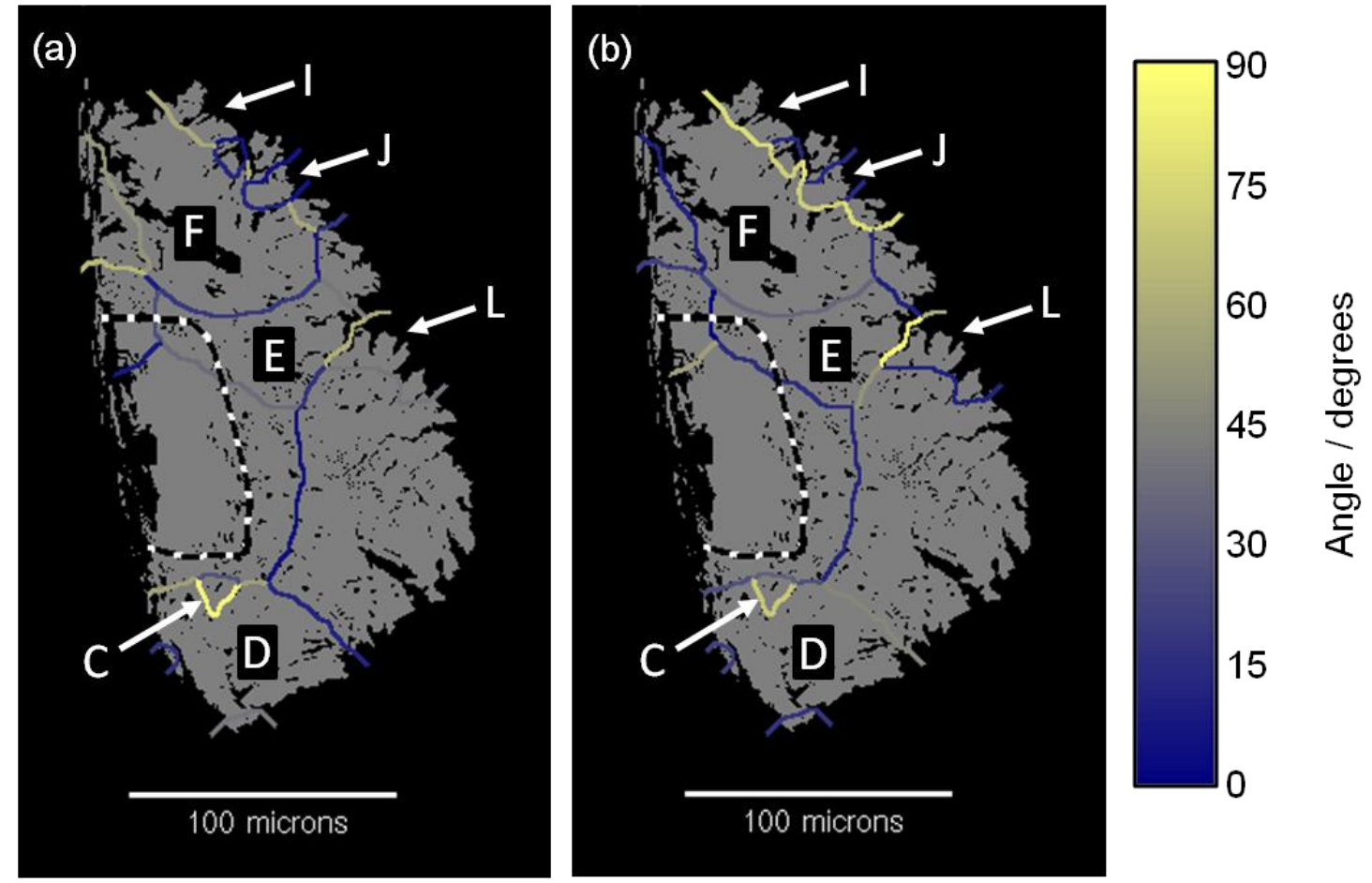

Figure 11. (a) Tilt and (b) twist angles for boundaries traversed by the crack.

between grain A and grain B. The effect on the crack growth rate is thus similar to that of two successive twist boundaries. In contrast, for grains F and D the crack propagates more rapidly on a single plane for most of the grain, only deviating near the edges.

This description is useful only close to the notch. In grain B the crack growth rate tends to increase as the crack develops in size. Here, it is judged that the high Schmid factor allows fast crack growth as the incompatibility to the notch, and hence the effect of the notch twist angle, becomes less significant with distance.

\section{Perspectives}

This is a preliminary study, making use of the new technique of diffraction contrast tomography. It demonstrates that the crack growth rates are sensitive to the local environment of the grains and the geometry of the crack, in particular that stage I crack propagation is retarded at grain boundaries with large misorientations of the basal slip plane. It reveals the potential for studies to observe the behaviour of longer cracks, and their interaction with obstacles in the microstructure. In future studies, it would be interesting to observe how the crack interacts with low Schmid factor grains (e.g. grain I). If the crack arrests at such a grain boundary and then subsequently reinitiates, studies of this type might identify the mechanism by which the obstacle is overcome, whether by local twinning, prismatic slip, or another failure mode. This would extend the work of Iida et al to a polycrystalline context [24]. The behaviour at boundaries with high twist and low tilt angles and the effects of texture in wrought material are also of interest. A logical direction to pursue will be finite element modelling to estimate the true local crack tip strains and the correlation with growth 


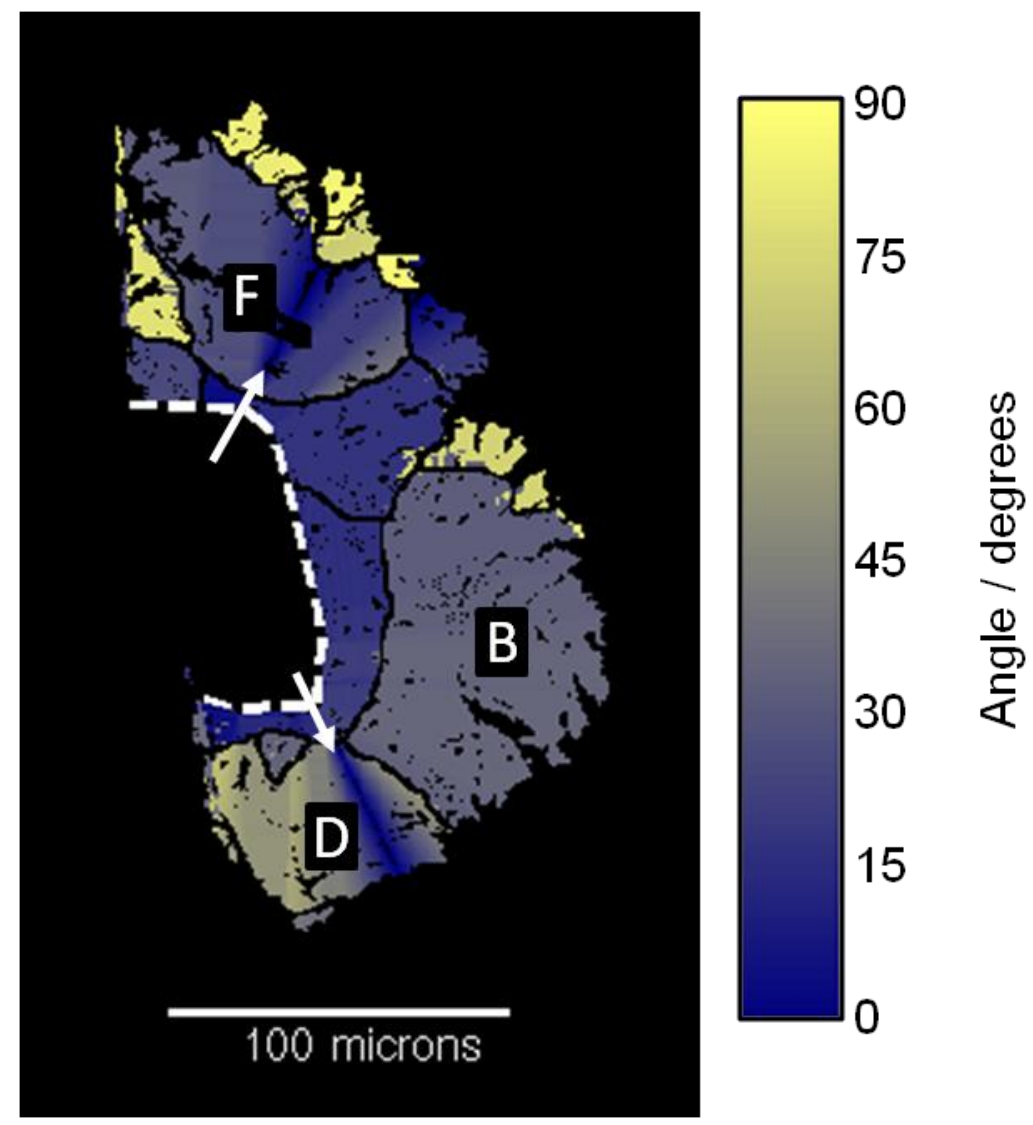

Figure 12. The notch twist angle for all grains traversed by the crack, assuming radial growth from the edges of the notch.

rates. It also may be interesting to use 3D image correlation to study the strains around the crack tip, using the precipitates as markers.

\section{Conclusion}

The combined use of diffraction contrast tomography and synchrotron microtomography provides unique opportunities for the in-situ study of short fatigue cracks, since it gives high-resolution access to the grain structure and grain boundary characteristics, the crack plane and the local crack growth rate. This study shows that by using these microstructure parameters, a qualitative explanation for the observed 3D behaviour of a short stage I fatigue crack can be obtained.

\section{Acknowledgements}

This work was supported by the UK Research Council funded project "Crack Nucleation and Short Crack Behaviour by Non-Destructive In Situ Observation" (EP/C002946/1). AAK is grateful to the Higher Education Commission of Pakistan for supporting his studies at Manchester University. Much of the analysis was carried out while AK was employed by GKSS (now HZG), Geesthacht, Germany. The material was kindly supplied by Magnesium Elektron Ltd. The work was conducted while TJM was at the Materials Performance Centre, School of Materials, University of Manchester. 


\section{References}

[1] T. Zhai, A.J. Wilkinson, and J.W. Martin, A crystallographic mechanism for fatigue crack propagation through grain boundaries, Acta Mater. 48 (2000) 49174927.

[2] S. Suresh, Fatigue of Materials, second ed., Cambridge University Press, Cambridge, 1998.

[3] U. Krupp, Fatigue crack propagation in metals and alloys: microstructural aspects and modelling concepts, first ed., Wiley-VCH, Weinheim, 2007.

[4] D. Davidson, K. Chan, R. McClung, and S. Hudak, Small fatigue cracks, in I. Milne, R.O. Ritchie and B. Karihaloo (Eds.), Comprehensive structural integrity vol. 4, Elsevier, Amsterdam, (2003) 129-164

[5] J. Schijve, Fatigue of structures and materials, second ed., Springer-Verlag, Berlin Heidelberg, 2009

[6] J.C. Newman, The merging of fatigue and fracture mechanics concepts : a historical perspective, Aerospace Sciences, 34 (1998) 347-390.

[7] D.L. McDowell and F.P.E. Dunne, Microstructure-sensitive computational modelling of fatigue crack formation, International Journal of Fatigue 32 (2010) 1521-1542.

[8] P. Clement, J.P. Angeli, and A. Pineau, Short crack behavior in nodular cast-iron, Fatigue and Fracture in Engineering Material Structures 7(4) (1984) 251-65.

[9] M. Marx, W. Schaef and H. Vehoff, Procedia Eng. 2 (2010) 163-171.

[10] W. Schaef, M. Marx, H. Vehoff, A. Heckl and P. Randelzhofer, Acta Mater. 59(5) (2011) 1849-1861.

[11] S. Beretta, Propagation of short cracks in a high strength steel for railway axles. In: A. Neimitz, I.V. Rokach, D. Kocanda, and K. Golos, editors. ECF 14, Fracture Mechanics Beyond 2000, vol. 1. Sheffield, UK: EMAS Publishing; 2002, 217-224.

[12] Y. Nadot, J. Mendez, N. Ranganathan, and A.S. Beranger, Fatigue life assessment of nodular cast iron containing casting defects, Fatigue and Fracture in Engineering Material Structures 22(4) (1999) 289-300.

[13] T.J. Marrow, H. Četinel, S. Macdonald, P.J. Withers, A. Venslovas, and M.X. Leonavičius, X-ray tomography of short fatigue cracks in ductile iron. In: A. Neimitz, I.V. Rokach, D. Kocanda, and K. Golos, editors. ECF14, Fracture Mechanics Beyond, vol. 2. Sheffield, UK: EMAS Publishing; 2002, p. 443-50.

[14] S.R. Stock, X-ray microtomography of materials, International Materials Review 44 (1999) 141-164. 
[15] E. Maire, J.-Y. Buffière, L. Salvo, J.J. Blandin, W. Ludwig, and J.M. Letang, On the application of X-ray microtomography in the field of materials science, Advanced Engineering Materials 3(8) (2001) 539-546.

[16] Ludwig W, Buffière J-Y, Savelli S, Cloetens P. Study of the interaction of a short fatigue crack with grain boundaries in a cast $\mathrm{Al}$ alloy using $\mathrm{X}$-ray microtomography. Acta Mater 2003;51(3):585-98.

[17] T.J. Marrow, J.-Y. Buffière, P.J. Withers, G. Johnson, and D. Engelberg, High resolution X-ray tomography of short fatigue crack nucleation in austempered ductile cast iron, International Journal of Fatigue 26 (2004) 717-725.

[18] J.-Y. Buffière, E. Ferrie, H. Proudhon, and W. Ludwig, Three dimensional visualisation of fatigue cracks in metals using high resolution synchrotron X-ray microtomography, Materials Science and Technology 22(9) (2006) 1019-1024.

[19] M. Herbig, A. King, P. Reischig, H. Proudhon, E.M. Lauridsen, J. Marrow, J.-Y. Buffière, and W. Ludwig, 3-D growth of a short fatigue crack within a polycrystalline microstructure studied using combined diffraction and phase-contrast X-ray tomography, Acta Materialia 59 (2011) 590-601.

[20] W. Ludwig, S. Schmidt, E.M. Lauridsen and H.F. Poulsen, X-ray diffraction contrast tomography: a novel technique for three-dimensional grain mapping of polycrystals. I. Direct beam case, Journal of Applied Crystallography 41 (2008) 302309.

[21] G. Johnson, A. King, M. Goncalves Honnicke, J. Marrow and W. Ludwig, X-ray diffraction contrast tomography: a novel technique for three-dimensional grain mapping of polycrystals. II. The combined case, Journal of Applied Crystallography 41 (2008) 310-318.

[22] W. Ludwig, P. Reischig, A. King, M. Herbig, E.M. Lauridsen, G. Johnson, T.J. Marrow and J.-Y. Buffière, Three dimensional grain mapping by $\mathrm{X}$-ray diffraction contrast tomography and the use of Friedel pairs in diffraction data analysis, Review of Scientific Instruments 80 (2009) 033905.

[23] A. King, G. Johnson, D. Engelberg, W. Ludwig and J. Marrow, Observations of intergranular stress corrosion cracking in a grain-mapped polycrystal, Science 321 (2008) 382-385.

[24] N. Iida, S. Ando, M. Tsushida, H. Kitahara and H. Tonda, Key Engineering Materials Vols. 345-346 (2007) 307-310.

[25] C. Potzies and K.U. Kainer, Advanced Engineering Materials 6 (2004) 281-289.

[26] F. Yang, S.M. Yin, S.X. Li and Z.F. Zhang, Materials Science and Engineering A 491 (2008) 131-136.

[27] J. Koike, N. Fujiyama, D. Ando and Y. Sutou, Scripta Materialia 63 (2010) 747750. 
[28] A.A. Khan and T.J. Marrow, In-situ Observation of Damage Mechanisms by Digital Image Correlation during Tension and Low Cycle Fatigue of Magnesium alloys, 12th International Conference on Fracture, ICF12, 12-17 July (2009), Ottawa, Canada

[29] J.-C. Labiche, O. Mathon, S. Pascarelli, M.A. Newton, G.G. Ferre, C. Curfs, G. Vaughan, A. Homs and D.F. Carreiras, The fast readout low noise camera as a versatile $\mathrm{x}$-ray detector for time resolved extended $\mathrm{x}$-ray absorption fine structure and diffraction studies of dynamic problems in materials science, chemistry, and catalysis, Review of Scientific Instruments 78 (2007) 091301.

[30] X.-S.Wang and J.-H. Fan, Materials Science Forum 546-549 (2007) 77-80.

[31] ] X.-S.Wang and J.-H. Fan, International Journal of Fatigue 28 (2006) 79-86.

[33] K. Gall, G. Biallas, H.J. Maier, P. Gullett, M.F. Horstemeyer, D.L. Mcdowell and J. Fan, International Journal of Fatigue 26 (2004) 59-70.

[33] P. Neumann, Coarse slip model of fatigue, Acta Metallurgica 17 (1969) $1219-1225$.

[34] B.N. Cox and W.L. Morris, Engineering Fracture Mechanics 31(4) (1988) 591-610.

[35] K. J. Miller, Fatigue Fract. Engng Mater. Struct., 10(2) (1987) 93-113.

[36] K. J. Miller, Fatigue of Engineering Materials and Structures, 5(3) (1982) 223-232. 


\title{
Appendix: A Crack Advance Measurement Algorithm
}

\begin{abstract}
By meshing two subsequent measured crack front positions it is possible to map the connections between points on the two lines, which allows the crack velocity to be estimated as a function of position. The meshing algorithm proceeds by producing triangles with sides as short as is practically achievable in order to connect the two lines in the likely direction of crack growth.
\end{abstract}

\section{Method}

Given a set of points defining two measured lines, at successive time steps $t$ and $t+1$, a search may be made for the nearest point on line $t+1$ to each point on line $t$, as shown in figure A1.

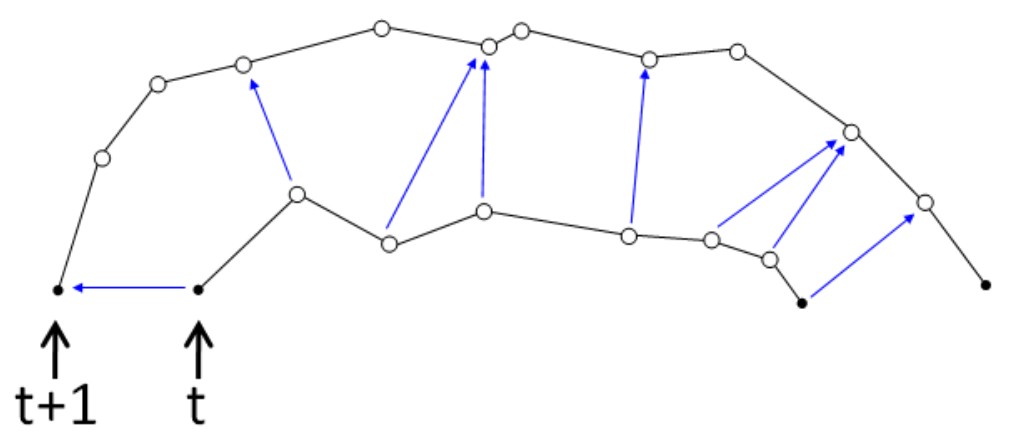

Figure A1. Initial search for nearest points on line $t+1$ to points on line $t$.

A similar search is then performed in reverse to find the nearest point on line $t$ to each point on line $t+1$, as shown in figure A2.

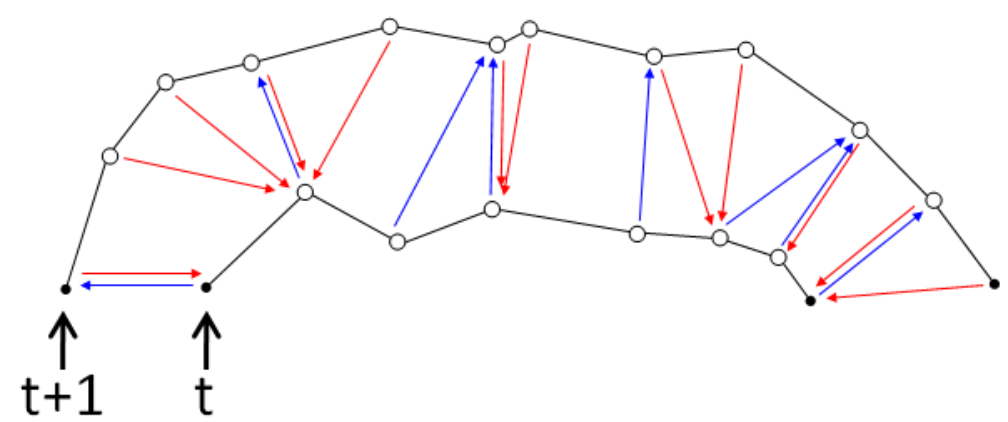

Figure A2. Initial search for nearest points on line $t$ to points on line $t+1$. 
Next, the common pairs of points in both searches that are mutual nearest neighbours are identified, as shown in Figure A2. These connections are used as seeds for the triangulation of the mesh.
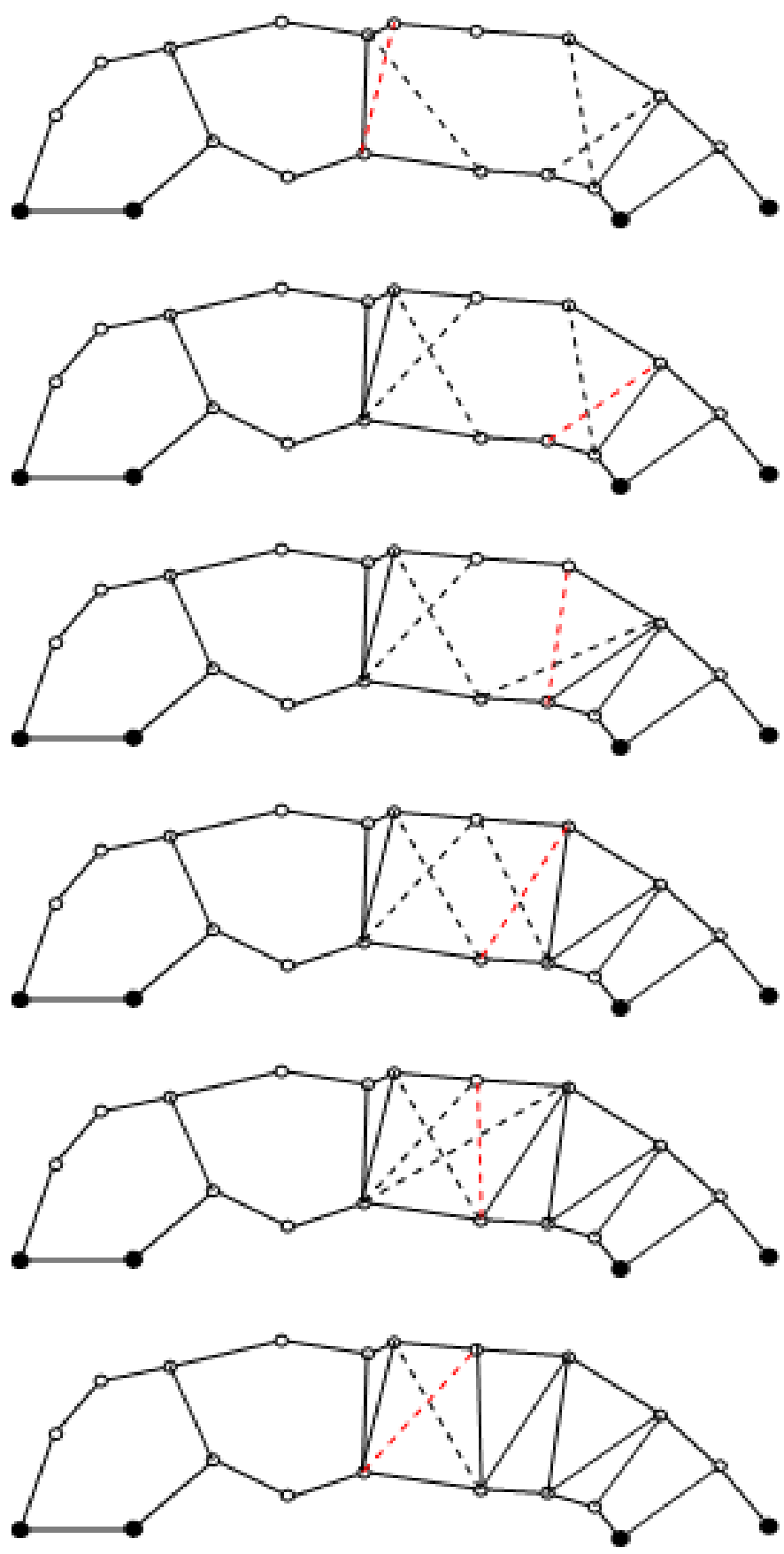

Figure A3. Triangulation proceeding from pairs identified as close contacts. 


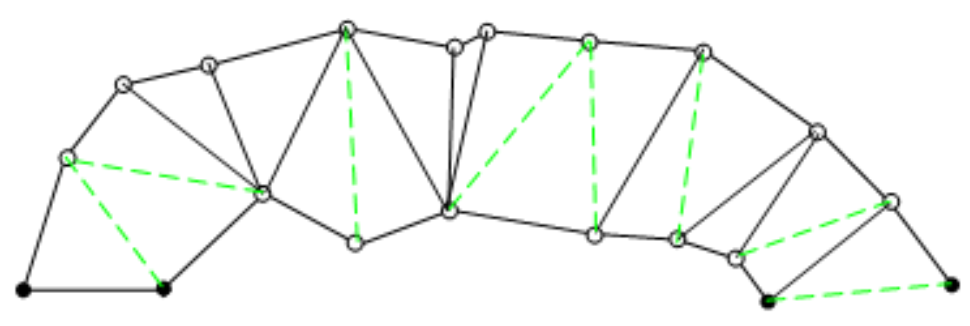

Figure A4. Longest triangle sides identified as giving crack velocity between two time steps.

The lines connecting these mutually nearest neighbours are identified and are used as an initial set to divide up the space along the two crack fronts. The regions between these lines are then triangulated by comparing the four possible lines that could be drawn to add a new triangle to the interior of each region, and adding the one which is the shortest, as shown in Figure A3. This is repeated for each region bounded by two close connections, or for regions at the starts or ends of the lines beginning with one close connection and advancing away from it.

The velocity at each point on the crack is then estimated using the longest line that begins at a particular point, as shown in figure A4, and the time between the two observations of the crack.

To increase the accuracy of the method, and to give connections that pass between the two lines closer to the normal angle (which is assumed to be most representative of the local growth rate), the initial point set is resampled to contain the original points plus a set of additional points distributed in between them in those regions where the average point spacing is greater than the average for the set. The facility exists to vary the criterion for adding points so as to resample segments greater than $1 / n$ times the average, where $n$ is user definable. In the analysis of data in this paper, $n=1$. 


\section{Table captions}

Table 3: Chemical Composition in weight percent.

Table 4: Mechanical Properties

\section{Figure captions}

Figure 1. Miniature fatigue sample mounted on beam line.

Figure 2. Reconstructed sections after (a) 500 and (b) 10,500 fatigue cycles, showing the crack growing from the FIB notch, and the microstructure of the material. The white particles are Nd-rich precipitates.

Figure 3. 3D rendering showing the crack (white) and the grains (coloured, semi-transparent). Colour denotes basal plane orientation according to the key in figure 4.

Figure 4. (a) Plan view of crack from along the loading ( $\mathrm{z}$ ) axis. The crack is coloured according to the basal plane orientation of the grains intersected by the crack. Black lines mark the grain boundaries. Superimposed white lines are the manually segmented crack fronts (increments of $\sim 1000$ cycles). The black lines are the grain boundary intersections with the surface. (b) The labels A-L that are used in the text to describe the grains. (c) The colour map used to display orientation (stereographic projection).

Figure 5. The local orientation of the crack plane. Colour represents the plane orientation relative to the sample, as in Figure 4.

Figure 6. Deviation between the crack plane and the crystallographic basal plane.

Figure 7. Development of crack surface length and depth with number of fatigue cycles extracted from tomography observations.

Figure 8. Local crack growth rate. Note that while the maximum observed rate was $40 \mathrm{~nm} / \mathrm{cycle}$, the colour scale varies between 0 and $20 \mathrm{~nm} / \mathrm{cycle}$ to better reveal local variations.

Figure 9. Schmid factor for the most activated basal slip system in each grain.

Figure 10. The calculation of twist and tilt angles in 3D. (a) Twist is the angle between the traces of the slip planes on the grain boundary. (b) Tilt is the remaining angle after applying the twst angle to one of the slip planes.

Figure 11 (a) Tilt and (b) twist angles for boundaries traversed by the crack. 
Figure 12. The notch twist angle for all grains traversed by the crack, assuming radial growth from the edges of the notch.

Figure A1. Initial search for nearest points on line $t+1$ to points on line $t$.

Figure A2. Initial search for nearest points on line $t$ to points on line $t+1$.

Figure A3. Triangulation proceeding from pairs identified as close contacts.

Figure A4. Longest triangle sides identified as giving crack velocity between two time steps. 